\title{
Prediction of Stope Stability Using Variable Weight and Unascertained Measurement Technique
}

\author{
Qian Kang, ${ }^{1,2}$ Yunmin Wang, ${ }^{2}$ Shuwen Zhang $\mathbb{D}^{1},{ }^{1}$ Chengzhi Pu, ${ }^{1}$ and Chuxuan Zhang ${ }^{1}$ \\ ${ }^{1}$ School of Resources \& Environment and Safety Engineering, University of South China, Hengyang, China 421001 \\ ${ }^{2}$ State Key Laboratory of Safety and Health for Metal Mines, Maanshan, China 243000 \\ Correspondence should be addressed to Shuwen Zhang; zhangshw1989@sina.com
}

Received 23 August 2020; Revised 18 December 2020; Accepted 4 January 2021; Published 18 January 2021

Academic Editor: Yanlin Zhao

Copyright (c) 2021 Qian Kang et al. This is an open access article distributed under the Creative Commons Attribution License, which permits unrestricted use, distribution, and reproduction in any medium, provided the original work is properly cited.

\begin{abstract}
A new model is established to analyze mining stope stability, using variable weight theory to calculate the index weight for each factor in different stopes and unascertained measure evaluation technique to predict the risk grade of stope stability. In this model, an evaluation index system by virtue of the 7 most important factors is established, including rock saturated uniaxial compressive strength, rock quality designation, rock joint and fissure, stope span, condition of pillar, groundwater seepage volume, and rate of supporting pit roof. And each index is divided into 5 grades by assignment value and the classification method of standardization. Accordingly, the analysis result is also classified into 5 risk grades. This model is used for the 6 main stopes from the $-270 \mathrm{~m}$ section in Xin-Qiao Mine, China. The results, giving risk grade for each stope and guiding the use of corresponding measures, avoided the problem of state out of balance caused by conventional invariable weight theory models and have ensured no accident occurred in mining production in recent years. This model can be used in other mines widely, by assigning values for the 7 factors on basis of current in situ cases.
\end{abstract}

\section{Introduction}

During recent decades, underground space stability problems in both mining industry and underground shelter of civil defense projects have drawn enormous attention [1-3]; therefore, it has been studied by many researchers globally. Research on the stability analysis not only ensures the safety of these underground structures but also provides guidelines to the design and construction of these structures economically. Although a lot of research has been performed in this area, yet, a general method that is able to consider some significant factors affecting the performance of underground space stability is still lacking. Underground mining stope stability analysis is the focus of this paper, which can also be extended to the applications of tunneling and other underground projects.
Stope stability is a crucial factor for selecting the mining method and ground pressure controlling method, which is closely related to the mining safety and efficiency. Many achievements of stope stability analysis have been obtained from traditional analysis methods, such as the data mining method $[4,5]$, fuzzy matter-element evaluation model [6], fuzzy-ideal point method [7], and numerical simulation [8, 9]. However, stope stability is, to a large extent, affected by geological conditions, mining method, ore structure, and many other ambiguous factors. Those factors are in mutual contact with variables and fuzzy characteristics and cannot be characterized quantitatively [10]. In addition to the complexity and systematic features of stope stability [10], these traditional analysis methods also exist some problems in the application such as complex calculation, narrow adaptive, and low credibility according to the above-mentioned 
references. To address those complicated problems, invariable weight theory which adopts an invariable index weight for each factor was adopted to analyze and resolve the stope stability [11]. However, there is an outstanding commonly encountered problem, i.e., out of balance [11], caused by the invariable weight theory. The fatal problems lead to the analysis results far from the reality with estimation value approaching to the borderline state, especially when a factor with low index weight plays an important role. This phenomenon affects the treatment measures dramatically and was particularly outstanding in Xin-Qiao Mine. Thus, a new analysis method and model should be provided to analyze the stope stability and other underground engineering.

In this study, a model combining variable weight theory [12] and unascertained measure evaluation is developed to analyze underground mining stope stability based on previous research. The 7 most important factors, including rock saturated uniaxial compressive strength, rock quality designation, rock joint and fissure, stope span, pillar property, groundwater seepage volume, and rate of supporting pit roof, are taken into consideration to establish the evaluation index system. The index weight of each factor was calculated using AHP (Analytic Hierarchy Process) and variable weight theory. Then, the risk grade prediction of stope stability was calculated according to the unascertained measure evaluation criteria. Variables and ambiguous factors influencing stope stability were taken into consideration in this model, which is in line with the engineering situation showing superiority to traditional models and methods. Compared to the invariable weight theory, this model can avoid the out of balance problem effectively according to the application in XinQiao Mine and provides a new approach for stope stability analysis.

\section{Analysis Model}

2.1. Unascertained Measure Evaluation Theory. The concept of unascertained information and its mathematical processing theory was first proposed by Wang [13]. Developed on the basis of mathematical processing theory, the unascertained measure method has been widely applied to the study of science and engineering [14-16]. Its theory can be expressed as follows:

Suppose $X_{1}, X_{2}, \cdots . . X_{n}$ are $n$ objects to be optimized, and the optimization object space is $\mathbf{X}=\left\{X_{1}, X_{2}, X_{3}, \cdots \cdots, X_{n}\right\}$. Each object of $X_{i}(i=1,2, \cdots, n)$ has $m$ evaluating indices, so the evaluating index space is $\mathbf{X}=\left\{x_{1}, x_{2}, x_{3}, \cdots \cdots, x_{m}\right\}$. Then, $X_{i}$ can be denoted as $m$-dimension $\mathbf{X}_{i}=\left\{x_{i 1}, x_{i 2}, x_{i 3}\right.$. $\left.\cdots \cdots, x_{i m}\right\}$, where $x_{i j}$ is the measured value of optimization object $\mathbf{X}_{i}$ with respect to the evaluating index $x_{j}$. The evaluation space is $\mathbf{U}$, denoted as $\mathbf{U}=\left\{C_{1}, C_{2}, \cdots \cdots, C_{p}\right\}$. Suppose $C_{k}$ $(k=1,2, \cdots, p)$ is the $k$ th evaluation grade, and the $k$ th grade is higher than the $(k+1)$ th one, denoted as $C_{k}>C_{k+1}$. If the grading rank $\left\{C_{1}, C_{2}, \cdots \cdots, C_{p}\right\}$ satisfies $C_{1}>C_{2}>\ldots \cdots>$ $C_{p}$ or $C_{1}<C_{2}<. . \cdots<C_{p},\left\{C_{1}, C_{2}, \cdots \cdots, C_{p}\right\}$ is called the ordered partition class of evaluation space $\mathbf{U}$.
2.2. Construction of Unascertained Measurement Function of a Single Index. Denote the unascertained measurement as $\mu_{i j k}=\mu\left(x_{i j} \in C_{k}\right)$, where $\mu_{i j}$ is the degree of $x_{i j}$ belonging to the $k$ th evaluation grade of $C_{k}$, which satisfies

$0 \leq \mu\left(x_{i j} \in C_{k}\right) \leq 1(i=1,2, \cdots, n ; j=1,2, \cdots, m ; k=1,2, \cdots, p)$,

$$
\begin{array}{r}
\mu\left(x_{i j} \in U\right)=1(i=1,2, \cdots, n ; j=1,2, \cdots, m), \\
\mu\left|x_{i j} \in \bigcup_{l=1}^{k} C_{l}\right|=\sum_{l=1}^{k} \mu\left(x_{i j} \in C_{l}\right)(k=1,2, \cdots, p) .
\end{array}
$$

Then, $\mu$ satisfying Equations (1)-(3) is called unascertained measurement, and $\left(\boldsymbol{\mu}_{i j k}\right)_{m \times p}$ is the unascertained measurement function of a single index:

$$
\left(\mu_{i j k}\right)_{m \times p}=\left[\begin{array}{cccc}
\mu_{i 11} & \mu_{i 12} & \cdots & \mu_{i 1 p} \\
\mu_{i 21} & \mu_{i 22} & \cdots & \mu_{i 2 p} \\
\vdots & \vdots & \ddots & \vdots \\
\mu_{i m 1} & \mu_{i m 2} & \cdots & \mu_{i m p}
\end{array}\right]
$$

2.3. Determination of Weight. The invariable weight vector that was used in the previous analysis model reflected the relative importance of each factor under ideal status. The variable weight theory which was proposed by Wang [17] emphasizes the index weight of factor changes with the status value of factor. Due to allowing the weight to be variable, the theory can remedy the error of invariable weight decision. Therefore, some research has investigated the correlation theory between state variable weight vector and structure balance function. For example, the structure balance functions of sum, product, and exponential type were successfully applied [18-20].

Invariable weight can be calculated by the AHP method before variable weight calculation [21]. Then, a variable weight vector is constructed based on variable weight theory. Suppose factor state vector $X=\left(x_{1}, x_{2}, \cdots \cdots, x_{n}\right)$ satisfies the three definitions as follows [17]:

Definition 1. The $n$ mapping $w_{j}(j=1, \cdots, n),[0,1]^{n} \longrightarrow$ $[0,1],\left(x_{1}, \cdots, x_{n}\right) \longrightarrow w_{j}\left(x_{1}, \cdots, x_{n}\right)$ that satisfies normalization, continuity, and monotonicity is defined as a group variable weight.

(1) Normalization: $\sum_{j=1}^{n} w_{j}\left(x_{1}, \cdots, x_{n}\right)=1$

(2) Continuity: every variable of the vector $w_{j}\left(x_{1}, \cdots, x_{n}\right)$ $(j=1, \cdots, n)$ is continuous

(3) Monotonicity: the vector $w_{j}\left(x_{1}, w_{j}\left(x_{1}, \cdots, x_{n}\right)(j=1\right.$, $\cdots, n)$ is monotonically reduced or monotonously increased based on arguments $x_{j}$ 
Supposing $W(X)=\left(w_{1}(X), \cdots, w_{n}(X)\right)$ is a variable weight vector.

Definition 2. Suppose a mapping $S:[0,1]^{n} \longrightarrow[0,1]^{n}, X$ $\longrightarrow S(X)=\left(S_{1}(X), \cdots, S_{n}(X)\right)$ satisfies the next 3 conditions:

(1) $x_{i} \geq x_{j}=>\Longrightarrow S_{i}(X) \leq S_{j}(X)$

(2) Every argument of vector $S_{i}(X)(j=1, \cdots, n)$ is continuous

(3) To any invariable weight vector $W=\left(w_{1}, \cdots, w_{n}\right)$, Equation (5) satisfies Definition 1

$$
W(X)=\frac{W \cdot S(X)}{\sum_{j=1}^{n}\left(w_{j} S_{j}(X)\right)},
$$

where vector $W \cdot S(X)=\left(w_{1} S_{1}(X), \cdots, w_{n} S_{n}(X)\right)$ is called the Hadamard product.

So the mapping is a $n$-dimension penalty type state variable weight vector. The state variable weight vector is the gradient vector of a $m$-dimension real function. Then, the real function is the balance function. Based on two types of variable weight vector, penalty type balance function is defined as follows:

Definition 3. A mapping: $[0,1] m \longrightarrow \mathbf{R}$ (real number set) is a $m$-dimensional balance function. So the function has continuous partial derivations, and the gradient vector of this function is a state variable weight vector. Generally, balance function is constructed based on an actual situation. The steps of constructing balance function are as follows:

Step 1. Selecting the type of balance function from sum type, product type, and exponential type. value.

Step 2. Relationship between weight and factor state

Step 3. Selecting an appropriate adjusting factor.

2.4. Construction of Unascertained Measurement Function of Multiple Indices. Based on the unascertained measurement function of a single index and weight, the unascertained measurement function of multiple indices can be worked out as follows:

$$
\left(\mu_{i k}\right)_{n \times p}=\left[\begin{array}{cccc}
\mu_{11} & \mu_{12} & \cdots & \mu_{1 p} \\
\mu_{21} & \mu_{22} & \cdots & \mu_{2 p} \\
\vdots & \vdots & \ddots & \vdots \\
\mu_{n 1} & \mu_{n 2} & \cdots & \mu_{n p}
\end{array}\right],
$$

where $\boldsymbol{\mu}_{i k}$ satisfies $0 \leq \boldsymbol{\mu}_{i k} \leq 1$ and $\mu_{i k}=\sum_{i=1}^{n} W_{i} \cdot \mu_{i j k}(k=1$, $2, \cdots, p)$.

2.5. Credible Degree Identification and Result Judgment. In order to get the final results of the stope stability analysis, the credible degree criteria are introduced. Suppose $\lambda$ $(\lambda \geq 0.5$, generally take 0.5 or 0.6$)$ is denoted as the credible degree $([14])$. If the evaluation space $\left\{C_{1}, C_{2}, \cdots, C_{p}\right\}$ is ordered and meets $C_{1}>C_{2}>\cdots>C_{p}$, and let

$$
p_{0}=\min \left|p: \sum_{k=1}^{p} \mu_{i k}>\lambda, i=1,2, \cdots, n\right| \text {. }
$$

Then, $\mathbf{X}_{i}$ belongs to the $p_{0}$ th evaluating grade of $C_{p 0}$.

2.6. Construction of the Evaluation Index System. Stope stability is influenced not only by geological conditions but also by the mining method, ore structure, and so on. The evaluation index, which is outstanding and easy to obtain, should be taken into consideration to ensure as few indices as possible can reflect the most important and comprehensive information. The 7 most important factors, including rock saturated uniaxial compressive strength $\left(I_{1}\right)$, rock quality designation $\left(I_{2}\right)$, rock joint and fissure $\left(I_{3}\right)$, stope span $\left(I_{4}\right)$, pillar property $\left(I_{5}\right)$, groundwater seepage volume $\left(I_{6}\right)$, and the rate of supporting pit roof $\left(I_{7}\right)$, are chosen to construct the evaluation index system according to the practical situation in mines and a lot of previous studies (e.g., Refs. [6, 7, 9, 2224]) for Xin-Qiao Mine, being suitable for others. By means of assignment value, the qualitative index can be easily converted to a semiquantitative index which is used in the model mentioned above, so more accurate forecasting results are achieved. By the classification method of standardization, each index is divided into 5 grades with set $\left\{C_{1}, C_{2}, C_{3}, C_{4}\right.$, $\left.C_{5}\right\}$. And, the stope stability analysis result was also denoted into 5 grades as very stable (grade I), stable (grade II), general stable (grade III), unstable (grade IV), and extremely unstable (grade V).

The unascertained measurement functions of a single index are constructed to get the value of the analysis factors, on the basis of the unascertained measurement function and the classification in Tables 1 and 2. The unascertained measurement function of each quantitative index is illustrated in Figure 1. It should be noted that the unascertained measurement function of one certain quantitative index is shown in Figure 2, where $\beta_{\mathrm{i}}, \beta_{i+1}$, and $\beta_{i+2}$ are the average values of the corresponding grades based on the classification criterion (Table 1). According to the distance between the intersection point of the measured value $x_{0}$ and the measure function line and the $Y$-axis projection, the unascertained measure corresponding to the measured value can be obtained.

\section{Application}

3.1. Determination of the Evaluation Function of Unascertained Measurement. Xin-Qiao Mine is located in the special industrial area in Tongling City, Anhui Province, China. Our investigation selected the 6 main stopes from the $-270 \mathrm{~m}$ section as research subjects. The stope of Xin-Qiao Mine is shown in Figure 3. The index values of the 7 factors mentioned above are surveyed and given in Table 3 [25]. Then, the unascertained measurement function of a single index could be obtained, according to the classification criterion in Tables 1 and 2, Figure 1, and the values given in Table 3. 
TABLE 1: Classification criterion of quantitative indices.

\begin{tabular}{lccccc}
\hline $\begin{array}{l}\text { Classification } \\
\text { standard }\end{array}$ & $\begin{array}{c}\text { Saturated uniaxial } \\
\text { compressive strength }\left(I_{1}\right) \\
(\mathrm{MPa})\end{array}$ & $\begin{array}{c}\text { Rock quality } \\
\text { designation }\left(I_{2}\right) \\
(\%)\end{array}$ & $\begin{array}{c}\text { Stope span } \\
\left(I_{4}\right)(\mathrm{m})\end{array}$ & $\begin{array}{c}\text { Groundwater seepage volume } \\
\left(I_{6}\right)\left(\mathrm{L} \cdot \mathrm{min}^{-1} \cdot(10 \mathrm{~m})^{-1}\right)\end{array}$ & $\begin{array}{c}\text { The rate of supporting } \\
\text { pit roof }\left(I_{7}\right)(\%)\end{array}$ \\
\hline$C_{1}$ & $>200$ & $\geq 90$ & $\leq 10$ & $\leq 5$ & $\geq 70$ \\
$C_{2}$ & $200 \sim 100$ & $90 \sim 75$ & $15 \sim 10$ & $10 \sim 5$ & $60 \sim 70$ \\
$C_{3}$ & $100 \sim 50$ & $75 \sim 50$ & $30 \sim 15$ & $25 \sim 10$ & $50 \sim 60$ \\
$C_{4}$ & $50 \sim 25$ & $50 \sim 25$ & $50 \sim 30$ & $50 \sim 25$ & $35 \sim 50$ \\
$C_{5}$ & $\leq 25$ & $<25$ & $>50$ & $>50$ & $<35$ \\
\hline
\end{tabular}

TABLE 2: Classification criterion of qualitative indices.

\begin{tabular}{|c|c|c|c|}
\hline $\begin{array}{l}\text { Classification } \\
\text { standard }\end{array}$ & Value & Situation of joint development $\left(I_{3}\right)$ & Situation of pillar $\left(I_{5}\right)$ \\
\hline$C_{1}$ & 1 & Joint is undeveloped, joint spacing $\geq 3 \mathrm{~m}$ & Rock is completed and no fracture \\
\hline$C_{2}$ & 2 & $\begin{array}{l}\text { Joint is undeveloped, joint spacing } 1 \sim 3 \mathrm{~m} \text {, rocks are cut into } \\
\text { giant block rock }\end{array}$ & There are some fractures around the corner \\
\hline$C_{3}$ & 3 & $\begin{array}{l}\text { Joint is little developed, joint spacing } 0.4 \sim 1 \mathrm{~m} \text {, rocks are cut } \\
\text { into block rock }\end{array}$ & $\begin{array}{l}\text { There are cracks on the pillar, and the crack } \\
\text { widths }<5 \mathrm{~mm}\end{array}$ \\
\hline$C_{4}$ & 4 & $\begin{array}{l}\text { Joint is developed, joint spacing } 0.2 \sim 0.4 \mathrm{~m} \text {, rocks are cut } \\
\text { into stone }\end{array}$ & $\begin{array}{l}\text { There are cracks on the pillar, and the crack widths } \\
\text { are } 5-10 \mathrm{~mm}\end{array}$ \\
\hline$C_{5}$ & 5 & $\begin{array}{l}\text { Joint is very developed, joint spacing }<0.2 \mathrm{~m} \text {, rocks are cut } \\
\text { into crushed stone }\end{array}$ & $\begin{array}{l}\text { The pillar is broken into bulk, the expansion of } \\
\text { fracture through the pillar }\end{array}$ \\
\hline
\end{tabular}

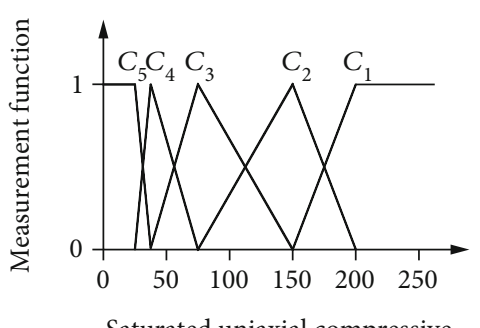

Saturated uniaxial compressive strength $(\mathrm{MPa})$

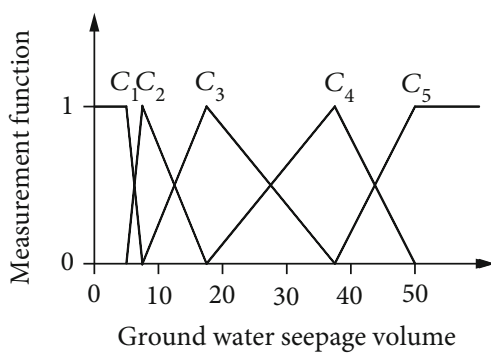

$\left(\mathrm{L} \cdot \mathrm{min}^{-1} \cdot(10 \mathrm{~m})^{-1}\right)$
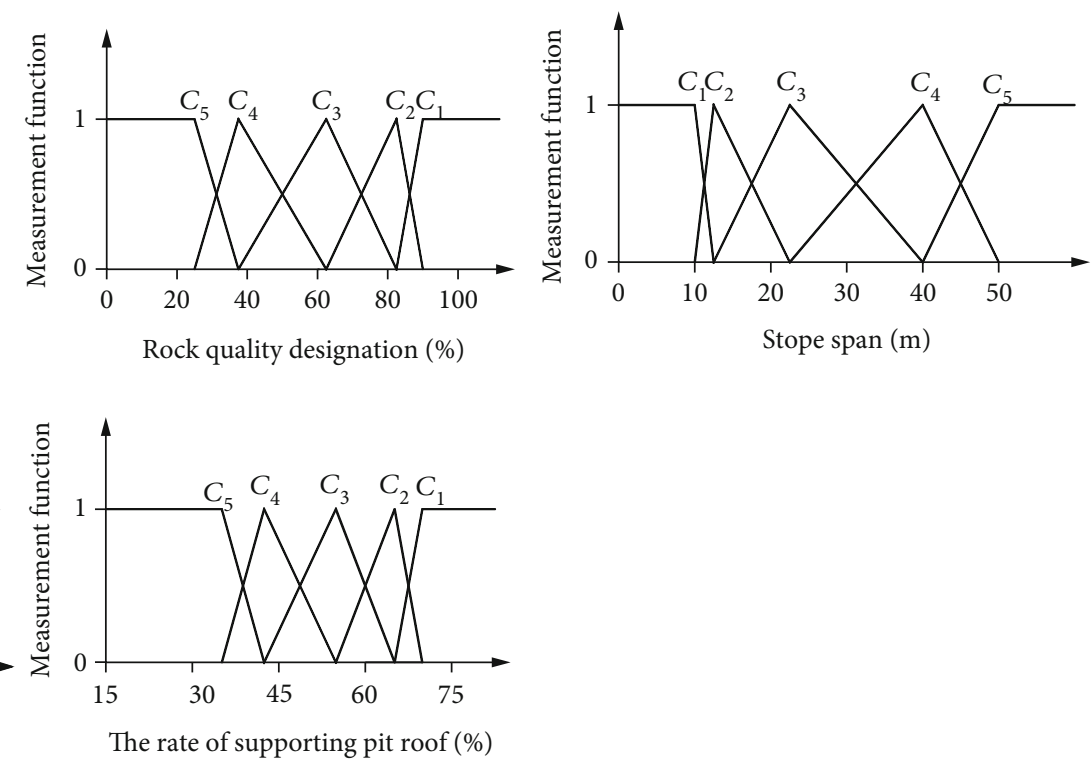

FIGURE 1: Unascertained measurement function of each quantitative index. 


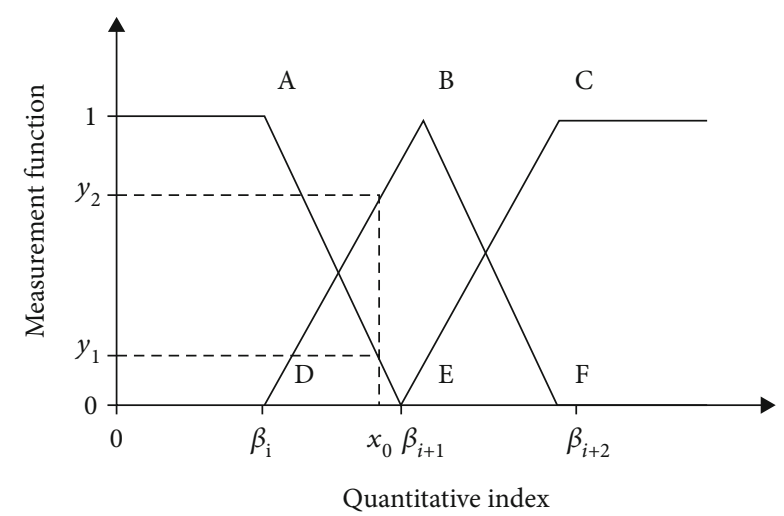

FIGURE 2: Unascertained measurement function of one certain quantitative index.

Taking W501 stope as an example, the evaluation function of unascertained measurement was calculated as

$$
\left(\mu_{1 j k}\right)_{7 \times 5}=\left[\begin{array}{ccccc}
0 & 0 & 0.3581 & 0.6419 & 0 \\
0 & 0 & 0.3800 & 0.6200 & 0 \\
0 & 0 & 1 & 0 & 0 \\
0 & 0.9500 & 0.0500 & 0 & 0 \\
0 & 1 & 0 & 0 & 0 \\
0 & 0.1300 & 0.8700 & 0 & 0 \\
0 & 0.9902 & 0.0098 & 0 & 0
\end{array}\right] .
$$

3.2. Calculation of Invariable Weight. Based on AHP, the decision matrix, which utilizes the ratio form to express the relative importance of two indices $([26,27])$, was given as

$$
[D]=\left[\begin{array}{rrrrrrr}
1 & 5 / 3 & 10 / 9 & 7 / 4 & 7 / 5 & 1 & 5 / 4 \\
3 / 5 & 1 & 4 / 5 & 7 / 6 & 7 / 6 & 10 / 7 & 5 / 4 \\
9 / 10 & 5 / 4 & 1 & 7 / 5 & 7 / 5 & 9 / 10 & 10 / 9 \\
7 / 4 & 6 / 7 & 5 / 7 & 1 & 5 / 4 & 2 / 3 & 2 / 3 \\
5 / 7 & 6 / 7 & 5 / 7 & 4 / 5 & 1 & 4 / 7 & 6 / 7 \\
1 & 2 / 3 & 10 / 9 & 3 / 2 & 7 / 4 & 1 & 5 / 3 \\
4 / 5 & 4 / 5 & 9 / 10 & 3 / 2 & 7 / 6 & 3 / 5 & 1
\end{array}\right]
$$

The index weight of the 7 factors $\mathbf{W}$ was determined by AHP: $\mathbf{W}=\{0.180,0.144,0.157,0.111,0.110,0.167,0.131\}$.

\subsection{Calculation of Variable Weight}

3.3.1. Normalization of Index Matrix. Only data in the same dimension and unit can be compared. Normalization processing must be made for contrast in the data that has different dimensions and units. Standard decision matrix $B=\left(b_{i j}\right)_{m \times n}$ can be treated as follows:

$$
\begin{aligned}
& \text { Benefit index (larger means better): } b_{i j}=\frac{a_{i j}-\min \left(a_{i j}\right)}{\max _{i}\left(a_{i j}\right)-\min _{i}\left(a_{i j}\right)}, \\
& \text { Cost index (smaller means better) }: b_{i j}=\frac{\max \left(a_{i j}\right)-a_{i j}}{\max _{i}\left(a_{i j}\right)-\min _{i}\left(a_{i j}\right)} .
\end{aligned}
$$

Through normalization processing of data, a normalized index matrix is obtained in Table 4 .

3.3.2. Construction of Variable Weight Vector. Constructing a variable weight vector is the foundation of using variable weight theory. Index variable weight vector has some advantages such as good extension ability and flexible parameter setting. Index variable weight vector was chosen in this paper. The variable weight vector, $S\left(X_{i}\right)=\left(\mathrm{S}_{1} X_{i}\right),\left(\mathrm{S}_{2} X_{i}\right), \cdots$, $\left.S_{n}\left(X_{i}\right)\right)$, can express as follows:

$$
S_{j}\left(X_{i}\right)=\left\{\begin{array}{l}
e^{-\alpha\left(x_{i j}-\beta\right)}\left(x_{i j} \leqslant \beta\right), \\
1\left(x_{i j}>\beta\right),
\end{array}\right.
$$

where $j=1, \cdots, n ; \alpha \geq 0 ; 0<\beta \leq 1, \beta$ is negative level. When the state values $x_{i j}$ of $j$ index is less than $\beta$, the weight of $j$ index improves through using the variable weight vector. The $\alpha$ which is called penalty level reflects the index balance of decision directly. And the bigger the $\alpha$ value, the more significant the penalty effect. In real application, $\alpha$ and $\beta$ were set based on decision requirements.

3.3.3. Calculation of Variable Weight. According to the characteristics of this decision, take $\alpha=0.9, \beta=0.15$, so variable weight can be obtained for each stope.

$$
\begin{aligned}
\mathbf{W}_{W 501} & =\{0.187,0.142,0.154,0.109,0.112,0.168,0.128\}, \\
\mathbf{W}_{W 507} & =\{0.178,0.143,0.155,0.112,0.109,0.166,0.137\}, \\
\mathbf{W}_{E 01} & =\{0.183,0.143,0.156,0.110,0.110,0.167,0.131\}, \\
\mathbf{W}_{E 07} & =\{0.184,0.147,0.155,0.109,0.108,0.165,0.132\}, \\
\mathbf{W}_{E 16} & =\{0.180,0.144,0.157,0.111,0.110,0.167,0.131\}, \\
\mathbf{W}_{E 23} & =\{0.175,0.140,0.160,0.110,0.117,0.170,0.128\},
\end{aligned}
$$

where $\mathbf{W}_{W 501}, \mathbf{W}_{W 507}, \mathbf{W}_{E 01}, \mathbf{W}_{E 07}, \mathbf{W}_{E 16}$, and $\mathbf{W}_{E 23}$ are the variable weights for the 6 stopes considered in this paper. 

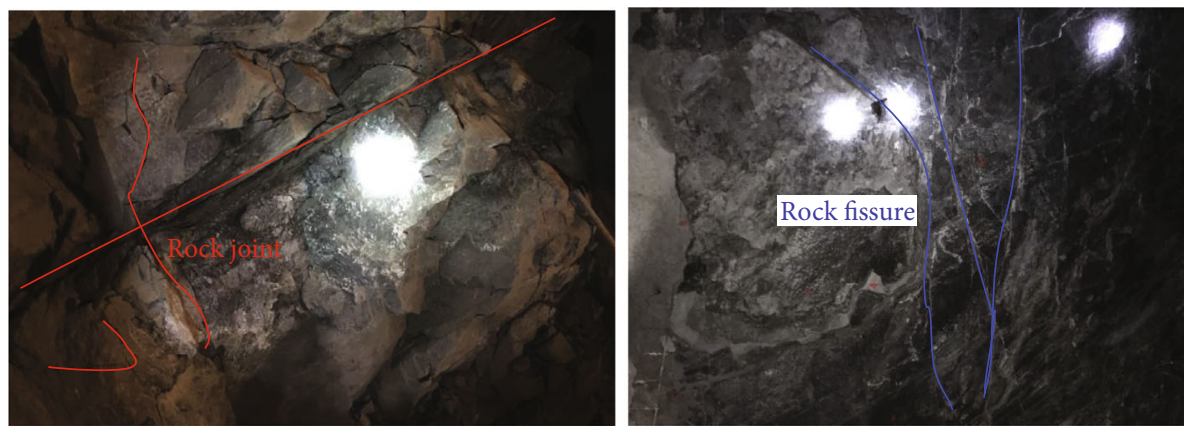

Figure 3: The stope of Xin-Qiao Mine.

TABLE 3: Index values.

\begin{tabular}{lccccccc}
\hline No. & $I_{1}(\mathrm{MPa})$ & $I_{2}(\%)$ & $I_{3}$ & $I_{4}(\mathrm{~m})$ & $I_{5}$ & $\begin{array}{c}I_{6}\left(\mathrm{~L} \cdot \mathrm{min}^{-1} \cdot\right. \\
\left.(10 \mathrm{~m})^{-1}\right)\end{array}$ & $I_{7}(\%)$ \\
\hline W501 & 50.7 & 47 & 3 & 13 & 2 & 27.3 & 80 \\
W507 & 94.7 & 64 & 4 & 10 & 3 & 32.7 & 30 \\
E01 & 76.8 & 66 & 3 & 12 & 4 & 32.7 & 55 \\
E07 & 65.3 & 38 & 4 & 14 & 4 & 53.1 & 40 \\
E16 & 160 & 51 & 4 & 16 & 4 & 63.8 & 45 \\
E23 & 155 & 73 & 2 & 10 & 1 & 22.6 & 75 \\
\hline
\end{tabular}

TABLE 4: Normalized index matrix.

\begin{tabular}{lccccccc}
\hline No. & $I_{1}$ & $I_{2}$ & $I_{3}$ & $I_{4}$ & $I_{5}$ & $I_{6}$ & $I_{7}$ \\
\hline W501 & 0.084 & 0.139 & 0.150 & 0.173 & 0.111 & 0.118 & 0.246 \\
W507 & 0.157 & 0.189 & 0.200 & 0.133 & 0.167 & 0.138 & 0.092 \\
E01 & 0.127 & 0.195 & 0.150 & 0.160 & 0.222 & 0.141 & 0.169 \\
E07 & 0.108 & 0.112 & 0.200 & 0.187 & 0.222 & 0.229 & 0.123 \\
E16 & 0.266 & 0.150 & 0.200 & 0.213 & 0.222 & 0.276 & 0.138 \\
E23 & 0.257 & 0.215 & 0.100 & 0.133 & 0.056 & 0.098 & 0.231 \\
\hline
\end{tabular}

Note: $I_{4}$ and $I_{6}$ are cost index.

3.3.4. Optimization Results Recognizing. The unascertained measurement function of multiple indices calculated from Equation (6) was given as

$\left(\mu_{i k}\right)_{6 \times 5}=\left[\begin{array}{ccccc}0.1290 & 0.2136 & 0.2838 & 0.3727 & 0.0000 \\ 0.1140 & 0.0575 & 0.4105 & 0.2821 & 0.1360 \\ 0.2220 & 0.1269 & 0.4365 & 0.4145 & 0.0000 \\ 0.0000 & 0.0927 & 0.1554 & 0.5383 & 0.2137 \\ 0.0360 & 0.2162 & 0.1434 & 0.4374 & 0.1670 \\ 0.3699 & 0.5181 & 0.1110 & 0.0000 & 0.0000\end{array}\right]$.

The credible degree was taken as 0.5. According to the variable and invariable weight theory and credible degree
TABLE 5: Analytically obtained risk grade of stopes' stability.

\begin{tabular}{lc}
\hline No. & Risk grade \\
\hline W501 & III \\
W507 & III \\
E01 & III \\
E07 & IV \\
E16 & IV \\
E23 & II \\
\hline
\end{tabular}

identification criteria, the risk grade of stope stability could be obtained in Table 5 .

Based on the analysis, the conclusions can be drawn as follows:

(1) E23 stope is stable, and the risk grade is allowable. Normal mining production and management are acceptable

(2) W501, W507, and E01 stopes are generally stable. The risk grade can be accepted, but with the continual supervision and monitor during mining

(3) E07 stope and E16 stope are unstable. The risk grade can be accepted reluctantly. Lots of measures must be taken, such as supporting stope, decreasing mining intensity, and increasing security monitoring efforts

(4) The four indices, including rock saturated uniaxial compressive strength $\left(I_{1}\right)$, groundwater seepage volume $\left(I_{6}\right)$, rock joint and fissure $\left(I_{3}\right)$, and rock quality designation $\left(I_{2}\right)$, are the most influential factors of stope stability

(5) The groundwater seepage volume $\left(I_{6}\right)$ of E07 stope and E16 stope are larger than others, the rock quality designation (RQD) of E07 stope is lower than others, and the supporting pit roof of W507 stope is lower than others. Then, the weights were changed in the calculation of variable weight for different stopes. If the risk grade cannot be accepted due to some indices tending to ultimate value, the workers must respond to the indices to reduce risk grade effectively 


\section{Conclusions}

From the research, the main conclusions can be drawn as follows:

(1) The evaluation index system is crucial in this work; the 7 most important factors mentioned above are taken into consideration in Xin-Qiao Mine, being suitable for others. Then, each index was divided into 5 grades by the means of assignment value and the classification method of standardization, and the analysis result was also denoted into 5 risk grades

(2) The weights were calculated by variable weight theory to avoid the "state out of balance" problem caused by invariable weight theory. The model was used in Xin-Qiao Mine, and the results show that this model has been improving the precision of stope stability analysis effectively and playing a good guiding role. The corresponding measures have been taken according to the research results to ensure that no accident occurred in mining production in recent years

(3) It is a new method to analyze stope stability, being practical and efficient, which can not only divide the stability grade of stope being produced but also reflect the risk grade about mining empty area objectively. The model can be used in other mines through assigning values for the 7 factors, and the evaluation index system and classification for each index can be improved to get better results

\section{Data Availability}

The table and figure data used to support the findings of this study are included within the article.

\section{Conflicts of Interest}

The authors declare that they have no conflict of interest.

\section{Acknowledgments}

The authors thank the financial supports from the National Natural Science Foundation program (Grant No. 51704168), the Natural Science Foundation of Hunan Province (Grant Nos. 2020JJ5494 and 2020JJ5490), the research project of the Education Department of Hunan Province (Grant Nos. 20 B517 and 18C0439), and the Open Research Fund Program of State Key Laboratory of Safety and Health for Metal Mines (Grant No. 2020-JSKSSYS-04).

\section{References}

[1] C. Zhang, P. Zou, Y. Wang, T. Jiang, H. Lin, and P. Cao, “An elasto-visco-plastic model based on stress functions for deformation and damage of water-saturated rocks during the freeze-thaw process," Construction and Building Materials, vol. 250, article 118862, 2020.

[2] Y. L. Zhao, Y. X. Wang, W. Wang, L. Tang, Q. Liu, and G. Cheng, "Modeling of rheological fracture behavior of rock cracks subjected to hydraulic pressure and far field stresses," Theoretical and Applied Fracture Mechanics, vol. 101, pp. 5966, 2019.

[3] C. Zhang, Y. Wang, and T. Jiang, "The propagation mechanism of an oblique straight crack in a rock sample and the effect of osmotic pressure under in-plane biaxial compression," Arabian Journal of Geosciences, vol. 13, no. 15, p. 736, 2020.

[4] E. Hoek, "Strength of rock and rock masses," ISRM News Journal, vol. 2, pp. 4-16, 1994.

[5] H. Sonmez and R. Ulusay, "Modifications to the geological strength index (GSI) and their applicability to stability of slopes," International Journal of Rock Mechanics and Mining Sciences, vol. 36, no. 6, pp. 743-760, 1999.

[6] Y. L. Zhao, C. S. Zhang, Y. X. Wang, and H. Lin, "Shear-related roughness classification and strength model of natural rock joint based on fuzzy comprehensive evaluation," International Journal of Rock Mechanics and Mining Sciences, no. article 104550, 2020.

[7] N. Mahadevan and K. A. Hoo, "Wavelet-based model reduction of distributed parameter systems," Chemical Engineering Science, vol. 55, no. 19, pp. 4271-4290, 2000.

[8] G. H. Sun, S. J. Cai, and W. B. Wang, "Simulation study on the mechanical stability of subsequent filling mining stope," in Rock Mechanics: Achievements and Ambitions, M. Cai, Ed., pp. 357-361, CRC Press, 2011.

[9] A. X. Wu, M. Q. Huang, B. Han, Y. M. Wang, S. F. Yu, and X. X. Miu, "Orthogonal design and numerical simulation of room and pillar configurations in fractured stopes," Journal of Central South University, vol. 21, no. 8, pp. 3338-3344, 2014.

[10] J. K. Dong, X. T. Feng, and X. W. Zhang, "Stability evaluation and parameter optimization on the fractured rock mass around underground stope," Journal of Northeastern University, vol. 34, pp. 1322-1326, 2013.

[11] W. R. Rutgers and I. de Jong, "Multi-tip sparker for the generation of acoustic pulses," Sensor Review, vol. 23, pp. 55-59, 2003.

[12] K. D. Liu, Q. K. Cao, and Y. J. Pang, "A method of fault diagnosis based on unascertained set," Acta Automatic Sinica, vol. 30, pp. 747-756, 2004.

[13] G. Y. Wang, "Uncertainty information and its mathematical treatment," Journal of Harbin Architecture and Engineering Institute, vol. 23, pp. 52-58, 1990.

[14] A. H. Liu, L. Dong, and L. J. Dong, "Optimization model of unascertained measurement for underground mining method selection and its application," Journal of Central South University, vol. 17, pp. 949-961, 2010.

[15] Y. J. Pang, L. M. Liu, and K. D. Liu, "Unascertained measurement evaluation model of environmental effection on Nujiang development," Journal of Central South University, vol. 42, pp. 1058-1062, 2011.

[16] J. Zhou and X. B. Li, "Integrating unascertained measurement and information entropy theory to assess blast-ability of rock mass," Journal of Central South University, vol. 19, no. 7, pp. 1953-1960, 2012.

[17] P. Z. Wang, Fuzzy Sets and Random Colony Shadow, Beijing Normal University Press, Beijing, China, 1985.

[18] H. X. Li, L. X. Li, J. Y. Wang, Z. W. Mo, and Y. D. Li, "Fuzzy decision making based on variable weights," Mathematical and Computer Modelling, vol. 39, no. 2-3, pp. 163-179, 2004. 
[19] J. C. Zhang, H. P. Qiu, and J. B. Quan, "The construction of balance function in variable weight theory," Fire Control and Command Control, vol. 32, pp. 108-110, 2007.

[20] K. S. You, L. Sun, and W. J. Gu, "Variable weight comprehensive evaluation method in the evaluation of road safety in the mountains," Systems Engineering, vol. 28, pp. 85-88, 2010.

[21] J. L. Peng, "Research on the optimization of green suppliers based on AHP and GRA," Journal of Chemical Information and Modeling, vol. 9, pp. 173-182, 2012.

[22] Y. L. Zhao, L. Y. Zhang, J. Liao, W. J. Wang, Q. Liu, and L. Tang, "Experimental study of fracture toughness and subcritical crack growth of three rocks under different environments," International Journal of Geomechanics, vol. 20, no. 8, article 04020128, 2020.

[23] W. Q. Peng, X. M. Wang, and W. J. Wang, "The supporting technology research in large section inclined shaft with fracture and soft surrounding rock," The Open Civil Engineering Journal, vol. 9, no. 1, pp. 450-456, 2015.

[24] Y. L. Zhao, L. Y. Zhang, W. J. Wang, Q. Liu, L. M. Tang, and G. Cheng, "Experimental study on shear behavior and a revised shear strength model for infilled rock joints," International Journal of Geomechanics, vol. 20, no. 9, article 04020141, 2020.

[25] X. M. Wang, The Research on Regularity and Control Technique of Ground Pressure Occurrence under Large Scale Filling Body (Report), School of Resources and Safety Engineering, Central South University, Changsha, 2013.

[26] H. Lee and M. Tom, "Robust adaptive control using a universal approximator for SISO nonlinear systems," IEEE Transactions on Fuzzy Systems, vol. 8, pp. 88-93, 2000.

[27] J. Wang, A. B. Rad, and P. T. Chan, "Indirect adaptive fuzzy sliding mode control: part I: fuzzy switching," Fuzzy Sets and Systems, vol. 122, no. 1, pp. 21-30, 2001. 